\title{
Borrowing Personal Memories
}

\section{ALAN S. BROWN ${ }^{1}$, KATHRYN CROFT CADERAO ${ }^{1}$, LINDY M. FIELDS ${ }^{1}$ and ELIZABETH J. MARSH ${ }^{2}$}

${ }^{1}$ Department of Psychology, Dedman College, Southern Methodist University, Dallas, TX USA

${ }^{2}$ Department of Psychology and Neuroscience, Duke University, Durham, NC USA

\begin{abstract}
Summary: The present investigation documents memory borrowing in college-age students, defined as the telling of others' autobiographical stories as if they are one's own. In both pilot and online surveys, most undergraduates admit to borrowing personal stories from others or using details from others' experiences to embellish their own retellings. These behaviors appear primarily motivated by a desire to permanently incorporate others' experiences into one's own autobiographical record (appropriation), but other reasons include to temporarily create a more coherent or engaging conversational exchange (social connection), simplify conveying somebody else's interesting experience (convenience), or make oneself look good (status enhancement). A substantial percentage of respondents expressed uncertainty as to whether an autobiographical experience actually belonged to them or to someone else, and most respondents have confronted somebody over ownership of a particular story. Documenting memory borrowing is important as the behavior has potential consequences for the creation of false memories. Copyright (c) 2015 John Wiley \& Sons, Ltd.
\end{abstract}

Assume, for the moment, that you are hanging out with friends, sharing stories over pizza and beer. As the conversation turns to celebrity sightings, one of your friends tells about a chance encounter with Johnny Depp at a McDonalds while in California last July. He saw Johnny standing in line and walked over to tell him that he was a big fan and loved his Pirates of the Caribbean movies. Johnny seemed sheepish and joked that he thought nobody would notice him here at McDonalds. Jumping briefly into character, he grabbed the plastic knife off of his tray, made a couple of broad slashes in the air, and then stuck the knife through your friend's hamburger bun. After turning to walk away, Johnny looked over his shoulder with a wry smile and said to be careful about talking to strangers-you can never be sure who they really are.

There is a profound satisfaction in captivating an audience with a good story. If the topic of celebrity sightings came up in the context of another group of friends, would you be tempted to borrow this story and tell it as if it had happened to you? To preview, the present results suggest that the likely answer is 'yes', at least if you are a college student.

The roots of the present research are in investigations on conversational retellings that involve one's own experiences (Hyman \& Faries, 1992; Marsh \& Tversky, 2004) as well as others' experiences (e.g., Bartlett, 1932; Dudukovic, Marsh \& Tversky, 2004; Marsh, Tversky \& Hutson, 2005; cf. Marsh, 2007). That is, people often recount their memories in conversation, email, and other means of communicating with others. Labeled 'tuning' by social psychologists (Zajonc, 1960), story tellers customize their tales to adapt the presentation to both the audience and context (e.g., Hyman, 1994; Pasupathi, 2001; Pasupathi, Stallworth, \& Murdoch, 1998; Sedikides, 1990; Tversky \& Marsh, 2000; Vandierendonck \& Van Damme, 1988). Speakers can be selective in what they include, biased in how they tell things, and even add details that never happened.

*Correspondence to: Alan S. Brown, Department of Psychology, Southern Methodist University, Dallas, TX 75275, USA.

E-mail: abrown@smu.edu
Speakers are rather blasé about taking such liberties when retelling their memories in conversations. For example, when asked to record and judge the accuracies of retellings in a daily diary, undergraduates reported distorting most of their retellings $(61 \%)$ by adding, exaggerating, minimizing, or omitting details (Marsh \& Tversky, 2004). At least some of this practice probably reflects Gricean norms, whereby speakers should provide no more information than is necessary for present purposes (leading to omissions when retelling; Grice, 1989). This behavior appears to violate Gricean norms of truthfulness, but only to the extent that speakers consider such distortions to be falsehoods. Surprisingly, the speakers in the diary study only considered $42 \%$ of their stories to be inaccurate (Marsh \& Tversky, 2004), suggesting that it is an acceptable practice for retellings to include some modifications and distortions.

Our interest is in a possible extreme case of distortion in conversational retellings: borrowing stories from others and telling them as if they are one's own. We know that people sometimes end up believing that another person's experiences actually happened to them, such as when twins dispute ownership of a memory (Sheen, Kemp, \& Rubin, 2001). Disputes of memory ownerships are more common when the rememberers are similar-twins are more likely than are siblings or close friends to have this experience (Sheen et al., 2001). Twins want to claim ownership of memories of misfortunes or achievements but disown memories of wrongdoings (Sheen, Kemp, \& Rubin, 2006). While there are likely multiple routes to such memory disputes, one possibility is that one is more likely to borrow a story from someone close and become confused over time about the source of that memory.

Because story borrowing involves intentional fabrications, we turn to the literature on lying for some guidance. Lying in everyday conversation is ubiquitous, as derived from information in personal diaries kept for 1 week (DePaulo, Kashy, Kirkendol, Wyer \& Epstein, 1996). Nearly all respondents had lied at some point during the week, regardless of whether they were college students $(98 \%)$ or community members $(80 \%)$. This estimate is consistent with both diary 
findings (DePaulo et al., 1996; George \& Robb, 2008; Hancock Tom-Santelli \& Ritchie, 2004) and retrospective estimates (Serota, Levine \& Boster, 2010; cf. Kalish, 2004; Patterson \& Kim, 1991) that over $90 \%$ of participants report telling lies on a weekly basis. Lies occurred in one out of four conversational exchanges (see also Hancock et al., 2004, 26\%; George \& Robb, 2008, Study 1, 25\%, and Study $2,22 \%$ ) and were told to between a quarter and a third of one's conversational partners (DePaulo et al., 1996; George \& Robb, 2008; Hancock et al., 2004). Across studies, such lies were more common in oral than written communications and more self-centered (to enhance one's image) than othercentered (to protect another person).

Similar to storytellers' acceptance of errors in their conversational retellings (Marsh \& Tversky, 2004), DePaulo et al. (1996) discovered that their participants were nonchalant about lying. Most did not consider the act or consequences to be that serious, and three-quarters of their participants would not hesitate to tell the same lie again. Thus, two different literatures point to inaccuracies in conversation as both frequent and acceptable. Given this, our goal was to document whether memory borrowing occurs in conversation and, if so, to gain an understanding of what motivates it.

\section{Pilot study}

To take a preliminary look at story borrowing, a pilot investigation was conducted using 74 Duke University students (38 women; mean age $=19.6$ years; age range $=18-40$ years ). Participants received either credit towards a course requirement for experiment participation $(n=28)$ or monetary compensation for completing the survey outside of the university's student center $(n=46)$. The study protocol was approved by the Duke University Institutional Review Board, and all participants gave informed consent prior to taking the survey.

Participants were asked whether they had ever (a) borrowed an entire story and later retold it to others as if the events had actually happened to them (borrowed story), (b) borrowed details from another person's story and incorporated them into their own stories (borrowed details), (c) heard someone else telling one of the participant's own experiences as if it had happened to them (stolen story), or (d) heard someone else use details from the participant's life experience to embellish their own stories (stolen detail). When participants acknowledged any of the experiences, they were further asked (a) whether it was a singular experience or had happened repeatedly, (b) the reason(s), and (c) to give a brief description of the experience.

Over half of respondents $(56.8 \%)$ claimed to have borrowed either an entire story $(37.8 \%)$ or a story detail $(36.5 \%)$, with the vast majority of these individuals claiming that each behavior had occurred on more than one occasion $($ story $=82.1 \%$; detail $=85.2 \%$ ). A smaller percentage $(38.4 \%)$ had experienced story theft $(30.1 \%)$ and/or detail theft (16.4\%), and as with borrowed stories/details, most had this happen more than once (story $=86.4 \%$; detail $=91.7 \%$ ).

Respondents also provided their motivations for borrowing a story/detail, and these open-ended responses were coded by two research assistants, with disagreements resolved through mutual discussion. The most common reason focused on the nature of the story $(52.3 \%)$ and that it was borrowed because it was funny (interesting, outrageous, or cool). A fair number of incidents were borrowed for convenience $(29.3 \%)$, with the particular experience fitting well with the discussion topic at hand. On some occasions, the motivation was to impress others and get attention $(7.9 \%)$, while the remaining responses either were not codable or fell into a miscellaneous classification $(10.1 \%)$. This preliminary finding about motivations for borrowing was surprising, given the literature on lying (DePaulo et al., 1996). That is, the pilot suggests that stories are most often borrowed because they are personally entertaining, whereas the lying literature emphasizes that the main motivation is to impress others. However, such conclusions are premature because of the small sample size of the pilot.

Reasons for theft (story/detail) are not summarized here because these evaluations turned out to be too speculative and seemingly biased by the experience of being ripped off (people often thought their stories were stolen 'to impress'; $22.2 \%$ ). Also, while this pilot suggests that borrowing others' stories and story details is rather common, the requirement to provide an example may have discouraged some from acknowledging the experience. When asked to provide details of their borrowing/theft experience, a 'don't remember' or blank response occurred on a third of occasions $(33.8 \%)$, and many descriptions were too general or vague to code $(30.3 \%)$. Given these issues, our main survey did not request that an affirmative response be accompanied by a specific example.

Our goal in the main study was to query a large number of respondents about story borrowing and the motivations behind such behaviors, but we also wanted to obtain data on the possibility that boundaries between borrowed and real experiences can become blurred (source monitoring errors; Johnson, Hashtroudi, Lindsay 1993). Three items were added to address this issue, assessing whether one had ever (a) realized after telling a personal story that it had actually originated with somebody else, (b) been uncertain about whether an experience happened to oneself or to another person, and (c) had a dispute with another person over story ownership (such confrontations provide evidence that at least one person has forgotten a story's source). Anecdotal reports of inadvertent plagiarism (cryptomnesia) exist involving works of literature, music, or art (Bowers \& Hilgard, 1986; Brown \& Murphy, 1989; Taylor, 1965), but we wanted to know whether something similar may occur with personal experiences.

We also examine whether gender differences exist in borrowing personal memories. The autobiographical recall literature suggests that women recall a greater number of experiences than do men (Davis, 1999; Fujita, Diener, \& Sandvick, 1991; Pillemer, Wink, DiDonato \& Sanborn, 2003; Rubin \& Berntsen, 2009; Seidlitz \& Diener, 1998), as well as provide more detailed reports (Niedźwieńska, 2003; Sutin \& Robins, 2007; Wang, Hou, Tang \& Wiprovnick, 2011). Gender differences are clearly evidenced when recalling one's own experiences, but will such differences also be found in borrowing memories? Looking to the literature on lying for clues, 
although women view lying as less acceptable than do men (Levine, McCornack \& Avery, 1992), there is no gender difference in the frequency of self-reported lying among either college students (DePaulo et al., 1996) or a general population sample (Serota et al., 2010).

To preview, a retrospective survey was administered to examine college students' reports of borrowing others' stories and story details, witnessing one's own story being plagiarized and experiencing source confusions about story origins.

\section{METHOD}

\section{Participants}

A total of 447 undergraduate college students (75\% female) from Southern Methodist University were recruited from the Human Subjects Pool in the Psychology Department and were compensated for their participation by receiving extra course credit. The mean age of the participant sample was 19.7 years $($ median $=19$ years; range $=18-37$ years $)$.

\section{Procedure}

The survey was presented online using QUALTRICS software. Participants acknowledged informed consent prior to taking the survey, which was approved by the Institutional Review Board at Southern Methodist University. The survey contained six items (Table 1) accompanied by a two-stage response scale: 'have you ever' (yes/no) that branched to a frequency scale for 'yes' responses: once, a few times, and regularly. These items were embedded in a larger survey instrument on autobiographical experiences, and the remaining items will not be covered in the present report.

The first survey item is the one that originally piqued our interest: How often do individuals take an entire story that they have heard from another source and later pass it along as their own (Table 1, Question 1 or Q1: borrowed stories)? Q1 was followed immediately by an open-ended question requesting the reasons for borrowing. As in the pilot study, we also asked how often participants borrow just a portion or detail from someone else's story, rather than the entire story (Q2: borrowed details), and if they have ever experienced somebody else borrowing one of their own stories (Q3: stolen stories).

As noted earlier, three additional items addressed evidence of confusion regarding story ownership. One asked whether there were times where one tells a story, only to realize later that the experience was actually somebody else's (Q4: forgotten borrowing). The second asked whether the respondent had ever had difficultly discriminating whether an incident actually occurred to them or to somebody else (Q5: source uncertainty). The final question in this set covered overt ownership disagreement with another person about whether an incident happened to them or the other person (Q6: memory dispute).

\section{RESULTS}

\section{Reports of borrowing}

As shown in Table 1, nearly half of the respondents (46.5\%) claimed to have borrowed an entire story (Q1), and $32.7 \%$ suggested that they had borrowed a portion of someone else's story (Q2). Combined, 57.7\% of respondents reported borrowing a complete story, a detail, or both. Gender differences were found for both forms of borrowing: Men were more likely than women to borrow both entire stories (Q1; men $=62.2 \%$; women $=52.8 \%), \chi^{2}(1)=5.50, p<.05$, and parts of stories $(\mathrm{Q} 2$; men $=48.6 \%$; women $=39.3 \%), \chi^{2}(1)$ $=3.94, p<.05$. Among those persons who admitted borrowing a story or detail, most claimed to have done so more than once $($ story $=74.0 \%$; story detail $=80.7 \%$ ). Furthermore, people who admit borrowing entire stories were more likely to also admit borrowing details (48.0\%) compared with those who had never borrowed a story $(21.5 \%), \chi^{2}(1)=29.36$, $p<.01$.

\section{Reports of theft}

Surprisingly, more than half of those surveyed (53.0\%) claimed to have witnessed one of their own stories being plagiarized (Q3), and among those with this experience, a majority $(54.3 \%)$ had this happen on more than one occasion. Looking at the relationship between borrowing a story and

Table 1. Percentage positive responses to survey items

\begin{tabular}{|c|c|c|c|c|c|}
\hline Construct & Have you ever... & Yes $(\%)$ & Once $(\%)$ & Few times $(\%)$ & Regularly (\%) \\
\hline $\begin{array}{l}\text { (Q1) } \\
\text { Borrowed stories }\end{array}$ & $\begin{array}{l}\text { heard someone's personal experience and later told it } \\
\text { to others as if it happened to you? }\end{array}$ & 46.5 & 12.1 & 33.1 & 1.3 \\
\hline $\begin{array}{l}\text { (Q2) } \\
\text { Borrowed details }\end{array}$ & $\begin{array}{l}\text { altered your own story by including details from } \\
\text { others' similar experiences? }\end{array}$ & 32.7 & 6.3 & 23.7 & 2.7 \\
\hline $\begin{array}{l}\text { (Q3) } \\
\text { Stolen stories }\end{array}$ & $\begin{array}{l}\text { heard somebody tell about something that happened } \\
\text { to you, as if it had happened to them? }\end{array}$ & 53.0 & 24.1 & 25.4 & 3.4 \\
\hline $\begin{array}{l}\text { (Q4) } \\
\text { Forgotten borrowing }\end{array}$ & $\begin{array}{l}\text { described something that you thought happened to } \\
\text { you, but realized later that it had happened to } \\
\text { somebody else? }\end{array}$ & 30.6 & 16.8 & 13.8 & 0.0 \\
\hline $\begin{array}{l}\text { (Q5) } \\
\text { Source uncertainty }\end{array}$ & $\begin{array}{l}\text { been unsure whether an incident happened to you or } \\
\text { to someone else? }\end{array}$ & 27.1 & 5.4 & 21.0 & 0.7 \\
\hline $\begin{array}{l}\text { (Q6) } \\
\text { Memory dispute }\end{array}$ & $\begin{array}{l}\text { disagreed with someone over whether an incident } \\
\text { happened to you or to them? }\end{array}$ & 56.6 & 12.8 & 40.9 & 2.9 \\
\hline
\end{tabular}


witnessing one's story being stolen, those who have borrowed stories themselves are more likely to have witnessed someone stealing theirs $(60.7 \%)$ compared with those who have not borrowed a story $(45.8 \%)$, a difference that is marginally significant, $\chi^{2}(1)=3.53, p=.08$. There were no gender differences in reports of theft.

\section{Motivations for borrowing}

Following an admission of borrowing, respondents were asked to explain why they told another's story as their own. Most respondents provided one reason (79.1\%), although some gave two $(18.1 \%)$ or more $(2.9 \%)$. Two coders first evaluated all open-ended responses and derived six categories that captured all of the responses. The coders then went back through all responses again to classify each response into one of these categories. The coders agreed upon $89 \%$ of classifications after this second pass, and discrepancies were resolved through discussion. The percentages of the total responses are provided in Table 2, along with illustrations extracted from participants' responses. In $10 \%$ of cases, no reason was given, or the reason provided was difficult to classify ('other'), and these responses will not be discussed further.

The most common reason for borrowing was appropriation (38.4\% of responses), which involved permanently incorporating the incident into one's own autobiographical record either intentionally or unintentionally. Appropriation is distinct from the remaining reasons for sharing a borrowed story, which are more specific to a particular conversational context and likely to be ad hoc, without the intent of necessarily incorporating the story as one's own. The next most common reason for borrowing was to enhance social connection and accounted for over a quarter of the explanations (26.5\%). When relating a particular incident, inserting a disclaimer that this story actually happened to somebody else makes it sound less important, less personal, less dramatic, or more removed from the present conversation. Providing

Table 2. Reasons for borrowing stories

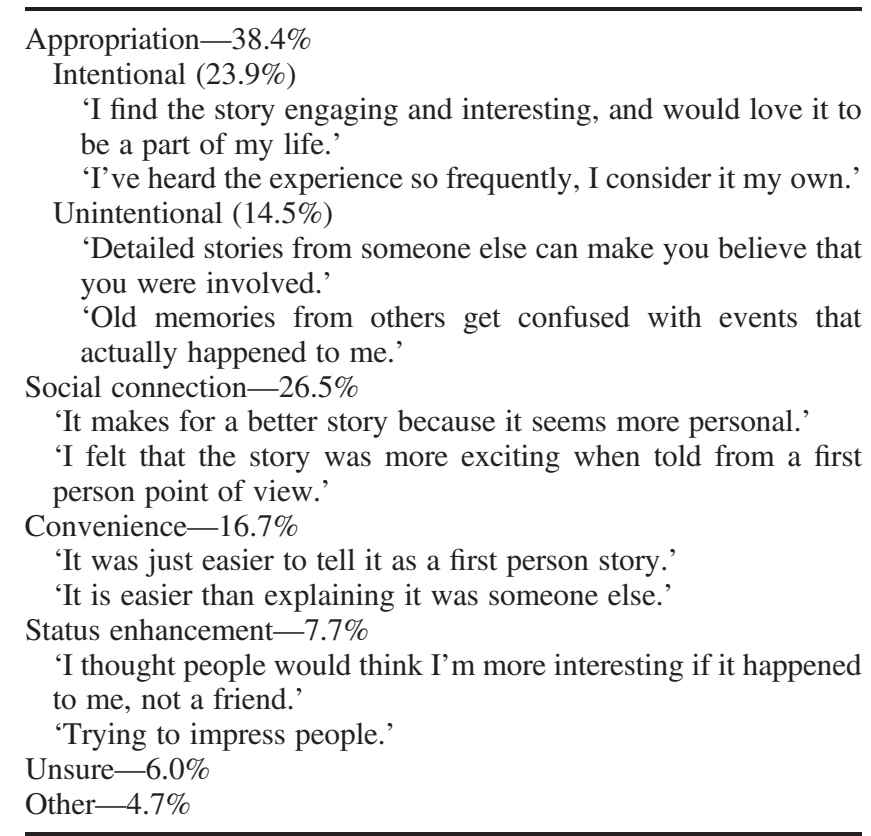

ownership details would be like explaining a joke-it loses its impact. Men (38.9\%) were more likely than women $(23.6 \%)$ to report this reason for borrowing, $\chi^{2}(1)=4.09$, $p<.05$ (there were no gender differences for any of the other reasons). The third most common explanation for borrowing was convenience (16.7\%): It is simply easier for a person to say that the experience happened to them rather than to someone else and skip the tedious documentation. The least frequent reason involved status enhancement, with the goal of making oneself look better. Given that the majority of lies are told to enhance one's personal status (Camden, Motley \& Wilson, 1984; DePaulo et al., 1996; Hample, 1980; Lippard, 1988; Turner, Edgley \& Olmstead, 1975), it was surprising that status enhancement was relatively uncommon.

\section{Awareness of source confusions}

The last survey items addressed the possibility that borrowed stories may be incorporated as one's own because of source confusion. Individuals sometimes catch themselves as having misappropriated others' stories after telling them: Over a quarter of respondents (30.6\%) confessed to conveying a story as if it were their own, only later to realize that it belonged to somebody else (Q4). The majority of those who reported such an experience claimed that it had only happened one time $(54.9 \%)$. Respondents had some sense of the possible role of source confusions, with more than a quarter $(27.1 \%)$ admitting to having been unsure about whether an experience was actually their own versus belonging to someone else (Q5). Furthermore, among those who had this happen, most had experienced it on more than one occasion $(80.1 \%)$.

Finally, disputes about memory ownership explicitly confirm source confusion, as both the respondent and another individual claim ownership of the same experience (Q6; Ikier, Tekcan, Gülgöz \& Küntay, 2003; Sheen et al., 2001). Memory disputes were rather common, with more than half $(56.6 \%)$ of respondents acknowledging that they had disagreed with someone over who an incident had happened to, and over three-quarters of this group (77.4\%) suggests that it had happened more than once. Men were significantly more likely than women to report such disputes $($ men $=62.2 \%$; women $=52.8 \%), \chi^{2}(1)=3.86, p<.05$, with no gender differences on the other source confusion items (Q4 and Q5).

\section{DISCUSSION}

The present investigation documents the existence of memory borrowing among college students: The majority have either borrowed someone else's entire experience as their own or embellished their personal life episodes with details of events that happened to others. This outcome replicates the findings from the pilot study, where over half of respondents also claimed to have borrowed a complete story or story details. Our findings suggest that borrowing stories (and details) is routine and acceptable among college students, who appear to be flexible in managing and adjusting their personal storytelling (Marsh \& Tversky, 2004). The high rate of witnessing others laying claim to one's own 
experiences $(53 \%)$ corroborates the general prevalence of borrowing. It also documents the loss of source information related to memory borrowing, assuming that one would not intentionally repeat the borrowed story in the presence of the source person if information about the story's origin had been retained. Alternatively, it is possible that when you witness your own story being stolen, it may actually represent a 'false accusation'. The true owners may be telling their story, and you forgot that you were the one who borrowed it from them. Although there is no way to confirm this possibility, the fact that those who borrow are significantly more likely to witness a theft of their own story certainly points in this direction. Finally, we found that most individuals who borrowed memories had done so on more than one occasion. It is unclear whether the repetition involved the same incident told repeatedly or different incidents. We assume that it was the latter, although it would be of value to clarify this in a subsequent investigation.

The most common reason for borrowing stories appears to be a desire to own a funny or entertaining anecdote. In fact, a number of respondents expressed story envy, and the act of retelling the coveted incident may represent an indirect effort to make this ownership a reality. Another important motivation involves social facilitation, or enhancing the degree of connection with one's audience (in the moment). Convenience also plays a role, in that it is easier to pretend that a story happened to you than to provide a complicated disclaimer that it actually happened to somebody else. People did not frequently report borrowing stories in order to enhance their own status, a finding in stark contrast to the literature on lying where self-serving reasons predominate: protecting one from embarrassment, loss of face, or disapproval, as well as making one appear to be a better person (DePaulo et al., 1996).

More generally, investigations on lying consistently suggest that over $90 \%$ of respondents self-report lying (DePaulo et al., 1996; George \& Robb, 2008; Hancock et al., 2004), whereas only $58 \%$ of our respondents reported borrowing stories or details. This difference is unlikely to be driven by methodology. While our data are derived from retrospective estimates, there is evidence that retrospective estimates and prospective (diary) records of lying are remarkably similar (Serota, Levine \& Bolster, 2010, Study 3). We speculate that borrowing from someone else's autobiographical episodes likely involves more cognitive demands (e.g., memory and editing) than the typical white lie, which may result in borrowing memories being less common than lying. Alternatively, the incidence of memory borrowing may be higher than our self-reports would indicate, as such episodes are more easily forgotten than lies or more likely to be incorporated as actual experiences.

Our findings also show that it can be difficult to keep track of a memory's source (self or other) over time. Several survey questions addressed blurred boundaries of story source or where borrowing may segue to ownership. A borrowed book that sits on our bookshelf sufficiently long may start to feel as if it belongs to us. Similarly, after holding on to and repeatedly retelling someone else's story, we may come to eventually feel comfortable claiming ownership. As one survey respondent pointed out, 'I've heard the experience so frequently, I consider it my own.' A progression from temporarily borrowed to permanently adopted may be a conscious decision on some occasions, but may reflect a more muddled process on others (cf. Mazzoni, Scoboria \& Harvey, 2010). Consistent with this speculation, more than a quarter of respondents admitted to realizing later that a story that they had told actually happened to somebody else (Q5), as well as being unsure about whether a particular story happened to them or somebody else (Q6). In fact, both of these findings suggest that our study may be underestimating the actual incidence of memory borrowing. Such speculation is supported by the fact that well over half of our respondents reported memory disputes over personal experiences. We may remain convinced that a borrowed memory is actually our own in the absence of confrontation. Illustrating this, Sheen et al. (2001) found that twins oftentimes found out that one of their memories is disputed only through participation in their study and suggest that '...disputed memories are a naturally occurring phenomenon that are discovered rather rarely and by accident...' (p. 786).

Some individual differences were found related to borrowing memories. As one might expect, respondents who borrow entire stories are also more likely to borrow details and witness others borrowing their stories, compared with those who did not borrow memories. A few gender differences were also found: A higher proportion of men report borrowing entire stories, parts of stories, and confronting others about story ownership. These three findings are congruent, in that if men borrow stories/details more often than do women, then men would have more opportunities to forget the story ownership and later tangle with the real owners. Furthermore, men are more likely than women to have borrowing motived by the enhancement of social connections. These differences are at odds with the lack of gender differences in the incidence of self-reported lying (DePaulo et al., 1996; Serota et al., 2010) but are congruent with the finding that lying is considered to be more acceptable by men than by women (Levine et al., 1992).

Similar to the way that false memories are reliably produced from information and suggestions provided by others (Loftus, 2005), perhaps we do something similar to ourselves by repeating our autobiographical thefts. Knowing initially that a story that we are telling did not actually happen to us does not necessarily provide protection from later believing that it did. For example, when diary participants are instructed to generate plausible but clearly false entries to mix in with their record of daily experiences, they subsequently misremember a fifth of these fictions as actually happening (Pernot-Marino, Danion \& Hedelin, 2004). Similarly, when participants generate fictitious stories about someone else, this later increases their belief that these experiences actually happened to them (Nourkova, Bernstein \& Loftus, 2004). These findings might give clues to the mechanisms whereby intentional borrowing can migrate into unintentional ownership.

Memory for the source of information declines more rapidly than its familiarity (Brown \& Halliday, 1991; Schacter, Harbluck \& McLaughlin, 1984). While the source tag for a borrowed story may originally be very clear (Johnson \& Raye, 1998), the act of retelling it as one's own creates a 
competing source tag. In the same way that embellishing another's idea makes it more likely later to be interpreted as one's own (Stark \& Perfect, 2006), telling someone else's story as one's own naturally modifies the experience by one's unique perspective, leading the 'self' context to gradually overwrite the 'other' context (Hyman, 1999):

...because self-generated fictitious events are likely to be influenced by a person's idiosyncratic knowledge and beliefs, the content of the made-up accounts may later be perceived as especially plausible and real (Zaragoza, Payment, Ackil, Drivdahl \& Beck, 2001, p. 476).

As one repeats a particular story, each telling enhances its familiarity, making it feel more like a personal experience. Nourkova et al. (2004) speculate that this may be an occupational hazard of writers, where '...making up a story about a fictional character may leave the novelist's own autobiographical memory vulnerable to contamination' (p. 78). More generally, by understanding the ways in which we tinker with our autobiographical records, we may gain insights into how we inadvertently alter our life stories. After all, that book that has made a home on your bookshelf for the past decade, and whose owner you no longer recall, may not officially be your own but can still be a treasured part of your story collection.

\section{REFERENCES}

Bartlett, F. C. (1932). Remembering: An experimental and social study. Cambridge: Cambridge University.

Bowers, K. S., \& Hilgard, E. (1986). Some complexities in understanding memory. In H. M. Pettinati (Ed.), Hypnosis and memory. New York: Guilford Press (pp. 3-18).

Brown, A. S., \& Halliday, H. E. (1991). Cryptomnesia and source memory difficulties. American Journal of Psychology, 104, 475-490.

Brown, A. S., \& Murphy, D. R. (1989). Cryptomnesia: Delineating inadvertent plagiarism. Journal of Experimental Psychology: Learning, Memory, and Cognition, 15, 432-442.

Camden, C., Motley, M. T., \& Wilson, A. (1984). White lies in interpersonal communication: A taxonomy and preliminary investigation of social motivations. Western Journal of Speech Communication, 48, 309-325.

Davis, P. J. (1999). Gender differences in autobiographical memory for childhood emotional experiences. Journal of Personality and Social Psychology, 76, 498-510.

DePaulo, B. M., Kashy, D. A., Kirkendol, S. E., Wyer, M. M., \& Epstein, J. A. (1996). Lying in everyday life. Journal of Personality and Social Psychology, 70, 979-995.

Dudukovic, N. M., Marsh, E. J., \& Tversky, B. (2004). Telling a story or telling it straight: The effects of entertaining versus accurate retellings on memory. Applied Cognitive Psychology, 18, 125-143.

Fujita, F., Diener, E., \& Sandvik, E. (1991). Gender differences in negative affect and well-being: The case for emotional intensity. Journal of Personality and Social Psychology, 61, 427-434.

George, J. F., \& Robb, A. (2008). Deception and computer-mediated communication in daily life. Communication Reports, 21, 92-103.

Grice, H. P. (1989). Studies in the way of words. Cambridge, MA: Harvard University Press.

Hample, D. (1980). Purposes and effects of lying. The Southern Speech Communication Journal, 46, 33-47.

Hancock, J. T., Tom-Santelli, J., \& Ritchie, T. (2004). Deception and design: The impact of communication technology on lying behavior. $\mathrm{CHI}$ Letters, 6, 129-134

Hyman, I. E., Jr. (1994). Conversational remembering: Story recall with a peer versus for an experimenter. Applied Cognitive Psychology, 8, 49-66.
Hyman, I. E., Jr. (1999). Creating false autobiographical memories: Why people believe their memory errors. In E. Winograd, R. Fivush, \& W. Hirst (Eds.), Ecological approaches to cognition: Essays in honor of Ulric Neisser (pp. 229-252). Hillsdale, NJ: Erlbaum.

Hyman, I. E., Jr., \& Faries, J. M. (1992). The functions of autobiographical memory. In M. A. Conway, D. C. Rubin, H. Spinnler, \& W. A. Wagenaar (Eds.), Theoretical principles on autobiographical memory (p. 207-221). Netherlands: Kluwer Academic Publishers.

Ikier, S., Tekcan, A. I., Gülgöz, S., \& Küntay, A. C. (2003). Whose life is it anyway? Adoption of each others' autobiographical memories by twins. Applied Cognitive Psychology, 17, 237-247.

Johnson, M. K., Hashtroudi, S., \& Lindsay, D. S. (1993). Source monitoring. Psychological Bulletin, 114, 3-28.

Johnson, M. K., \& Raye, C. L. (1998). False memories and confabulation. Trends in Cognitive Sciences, 2, 137-145.

Kalish, N. (2004, January). How honest are you? Reader's Digest, 114-119.

Levine, T. R., McCornack, S. A., \& Avery, P. B. (1992). Sex differences in emotional reactions to discovered deception. Communications Quarterly, 40, 289-296.

Lippard, P. V. (1988). "Ask me no questions, I'll tell you no lies": Situational exigencies for interpersonal deception. Western Journal of Speech Communication, 52, 91-103.

Loftus, E. F. (2005). Planting misinformation in the human mind: A 30-year investigation of the malleability of memory. Learning \& Memory, 12, 361-366.

Marsh, E. J. (2007). Retelling is not the same as recalling. Current Directions in Psychological Science, 16, 16-20.

Marsh, E. J., \& Tversky, B. (2004). Spinning the stories of our lives. Applied Cognitive Psychology, 18, 491-503.

Marsh, E. J., Tversky, B., \& Huston, M. (2005). How eyewitnesses talk about events: Implications for memory. Applied Cognitive Psychology, 19, 531-544.

Mazzoni, G., Scoboria, A., \& Harvey, L. (2010). Nonbelieved memories. Psychological Science, 21, 1334-1340.

Niedźwieńska, A. (2003). Gender differences in vivid memories. Sex Roles, 49, 321-331.

Nourkova, V., Bernstein, D. M., \& Loftus, E. F. (2004). Biography becomes autobiography: Distorting the subjective past. American Journal of Psychology, 117, 65-80.

Pasupathi, M. (2001). The social construction of the personal past and its implications for adult development. Psychological Bulletin, 127, 651-672.

Pasupathi, M., Stallworth, L. M., \& Murdoch, K. (1998). How what we tell becomes what we know: Listener effects on speakers' long-term memory for events. Discourse Processes, 26(1), 1-25.

Patterson, J., \& Kim, P. (1991). The day America told the truth. New York: Prentice-Hall.

Pernot-Marino, E., Danion, J., \& Hedelin, G. (2004). Relations between emotion and conscious recollection of true and false autobiographical memories: An investigation using lorazepam as a pharmacological tool. Psychopharmacology, 175, 60-67.

Pillemer, D. B., Wink, P., DiDonato, T. E., \& Sanborn, R. L. (2003). Gender differences in autobiographical memory styles of older adults. Memory, 11, 525-532.

Rubin, D. C., \& Berntsen, D. (2009). The frequency of voluntary and involuntary autobiographical memories across the life span. Memory \& Cognition, 37, 679-688.

Schacter, D. L., Harbluk, J. L., \& McLaughlan, D. R. (1984). Retrieval without recollection: An experimental analysis of source amnesia. Journal of Verbal Learning and Verbal Behavior, 23, 593-611.

Sedikides, C. (1990). Effects of fortuitously activated constructs versus activated communication goals on person impressions. Journal of Personality and Social Psychology, 58, 397-408.

Seidlitz, L., \& Diener, E. (1998). Sex differences in the recall of affective experiences. Journal of Personality and Social Psychology, 74, 262-271.

Serota, K. B., Levine, T. R., \& Boster, F. J. (2010). The prevalence of lying in America: Three studies of self-reported lies. Human Communication Research, 36, 2-25.

Sheen, M., Kemp, S., \& Rubin, D. C. (2001). Twins dispute memory ownership: A new false memory phenomenon. Memory \& Cognition, 29, 779-788. 
Sheen, M., Kemp, S., \& Rubin, D. C. (2006). Disputes over memory ownership: What memories are disputed? Genes, Brain and Behavior, 5, 9-13.

Stark, L., \& Perfect, T. J. (2006). Elaboration inflation: How your ideas become mine. Applied Cognitive Psychology, 20, 641-648.

Sutin, A. R., \& Robins, R. W. (2007). Phenomenology of autobiographical memories: The memory experiences questionnaire. Memory, 15, 390-411.

Taylor, F. K. (1965). Cryptomnesia and plagiarism. British Journal of Psychiatry, 111, 1111-1118.

Turner, R. E., Edgley, C. \& Olmstead, G. (1975). Information control in conversations: Honesty is not always the best policy. Kansas Journal of Sociology, 9, 69-89.
Tversky, B., \& Marsh, E. J. (2000). Biased retellings of events yield biased memories. Cognitive Psychology, 40, 1-38.

Vandierendonck, A., \& Van Damme, R. (1988). Schema anticipation in recall: Memory process or report strategy? Psychological Research, 50, 116-122.

Wang, Q., Hou, Y., Tang, H. \& Wiprovnick, A. (2011). Traveling backwards and forwards in time: Culture and gender in the episodic specificity of past and future events. Memory, 19, 103-109.

Zajonc, R. B. (1960). The process of cognitive tuning in communication. The Journal of Abnormal and Social Psychology, 61, 159-167.

Zaragoza, M. S., Payment, K. E., Ackil, J. K., Drivdahl, S. B., \& Beck, M. (2001). Interviewing witnesses: Forced confabulation and confirmatory feedback increase false memories. Psychological Science, 12, 473-477. 